\title{
TALLERES DE PSICOMOTRICIDAD EN AULAS DE INCLUSIÓN, EN UN PREESCOLAR ENRIQUECIDO POR LA DIVERSIDAD: FUNDACIÓN CENTRO SAN JUAN DE JERUSALÉN, QUITO - ECUADOR
}

\author{
Sonia Raquel Sigüenza Hinostroza
}

\begin{abstract}
RESUMEN
A continuación contamos la aplicación de talleres de psicomotricidad cuya población está conformada por niños con parálisis cerebral y sus compañeros niños regulares, todos pertenecientes al preescolar de la Fundación Centro San Juan de Jerusalén, institución pionera en educación inclusiva desde hace 25 años en Quito - Ecuador, trabajo psicoterapéutico, estructurante, seguro y contenedor donde los niños van a vivir experiencias motrices, sensoriales, corporales, lúdicas y emocionales que le van a permitir involucrar y volver a involucrar su cuerpo dentro de su dimensión psíquica y física, tomando en cuenta la presencia de los otros, la manera como estos talleres aportan al proceso de aprendizaje y adaptación social, a la construcción de autonomía y a la consolidación grupal de niños y niñas con discapacidad y sin ella, hermanados por su deseo de crecer y compartir.
\end{abstract}

\section{PALABRAS CLAVE}

Talleres, Psicomotricidad, Fundación San Juan, Educación Inclusiva, dimensión psíquica.

\section{ABSTRACT}

Then, we have the application of psychomotricity workshops whose population is made up of children with cerebral palsy and their regular children, all belonging to the preschool of the Fundación Centro San Juan de Jerusalén, pioneer institution in inclusive education for 25 years in Quito - Ecuador, psychotherapeutic, structuring, safe and container work where children will experience motor, sensory, body, playful and emotional experiences that will allow them to involve and reinvolve their body within their psychic and physical dimension, taking into account the presence of others, the way these workshops contribute to the process of learning and social adaptation, the construction of autonomy and the group consolidation of children with disabilities and without it, twinned by their desire to grow and share.

\section{KEYWORDS}

Workshops, Psychomotricity, Fundación San Juan, Inclusive Education, psychic. dimension.
$\mathrm{U}$ $\mathrm{n}$ patio de juegos del Preescolar,
equipado con juegos propicios para la
primera infancia, niños resbalando seguros por los módulos, y colchonetas, alfombra, rampas, el ruido de diez de la mañana, salen de las salas de terapia física ocupacional y lenguaje, y de las salas de aula de preescolar, bajo el acompañamiento de maestros y auxiliares, quienes van a motivar y facilitar al encuentro lúdico, entre los pequeños unos con posibilidades de movimiento libre y otros con limitaciones en su acción más no en su deseo de tener las aventuras que todo patio de juegos ofrece. Un pequeño caos se arma en este patio, en este iniciar de su vida social, todos van tras el mismo objetivo, ganar el triciclo, alcanzar la pelota, ingresar primeros en el túnel, alcanzar el tobogán, etc., el pequeño caos debe ser constantemente regulado por los adultos para que los accidentes no ocurran, y los ímpetus de cada quien no sean mayores que las necesidades grupales de compartir, de que todos los amigos se involucren en el juego. Ya que, en este patio de juegos, todos tienen derecho a la participación.

Se trata de la Fundación Centro San Juan de Jerusalén un lugar educativo-terapéutico donde se vive la inclusión de niños con parálisis cerebral y niños regulares que tienen las mismas necesidades: desarrollarse en un ambiente acogedor y estimulador. Y que más estímulo que sus compañeros de juego, algunos no caminan, otros no articulan palabras, otros tienen dificultades para quedarse quietos, otros muy hábiles para hacer amigos y hablar, aunque sus 
movimientos sean lentos, una variedad de capacidades, de inquietudes, todas son vidas floreciendo que nos retan a nuestro papel de adultos y de educadores o psicólogos a proponer espacios renovados de interacción que promueva el aprendizaje y el disfrute de crecer.

Esta Fundación recibe a niños en aulas llamadas de inclusión educativa, ya que una parte del grupo son niños que tienen diagnosticada alguna discapacidad sobre todo a nivel motor, como la parálisis cerebral, otros niños están cursando un desarrollo llamado normal, todos son compañeros y comparten las aulas del preescolar desde los dos hasta los cinco años, en donde tienen las primeras experiencias educativas y socializadoras que les prepararía para su educación formal a partir de los cinco años.

A nivel terapéutico son atendidos por especialistas de terapia física, ocupacional, de lenguaje, psicología; esta modalidad combinada entre lo educativo y terapéutico hace de este Centro un lugar privilegiado, acaso que serviría de modelo de atención, ya que las familias y los niños encuentran en un solo lugar la consolidación de estas necesidades.

De igual manera, podemos destacar al Centro San Juan de Jerusalén como una institución pionera en la inclusión escolar en Quito - Ecuador, allí fueron desarrollándose prácticas educativas inclusivas desde hace más de 25 años, alimentadas por los profesionales educadores, psicólogos y terapeutas convencidos de que el camino de la inclusión educativa es un camino de creatividad y de la búsqueda de respuestas que vayan ajustándose a los grupos tan diversos que resultan de la atención a la variedad de niños con y sin discapacidad.

Con la apertura de aulas de inclusión, se ha ido dando forma a una propuesta educativa más sólida, con una reflexión muy argumentada acerca de las premisas de la inclusión educativa y de la pedagogía constructivista, que ha dado paso a que se elaboren marcos de acogida y puesta en marcha de un proyecto educativo que tiene vida y que se auto-regula de acuerdo a los retos de la población que cada añollega.
Los padres de niños regulares, lejos de tener reticencia al encuentro con la discapacidad, van conociendo más y venciendo las fronteras mentales que muchas veces nacen de la falta de contacto con esta realidad, y vemos niños solidarios, familias amigas, vínculos que se fortalecen en este encuentro cuyo eje común es la educación y el sano desarrollo infantil.

En todo grupo humano la diversidad es una característica común, aunque suene contradictorio, lo que se explica es que en este Centro buscamos los ejes que nos hacen iguales en derechos y en participación; sin embargo, siempre marcados por las diferencias individuales, por la huella única que cada ser humano aporta, evitando una masificación que despersonaliza, pero si encontrando vías que nos unifiquen en un quehacer común. Como lo dice la Declaración de la UNESCO 2005 sobre Inclusión Escolar, la inclusión es el proceso de identificar y responder a la diversidad de las necesidades de todos los estudiantes a través de la mayor participación en el aprendizaje, las culturas, las comunidades y reduciendo la exclusión en la educación.

Dentro de este marco institucional que hemos descrito brevemente, se encuentran los niños quienes llegan con sus necesidades y con una serie de signos dados por la sociedad actual, nos plantean problemáticas nuevas, que tocan a su desenvolvimiento, a su manera de compartir o de aislarse, a su egocentrismo, a la forma de asimilar o no las órdenes, los horarios, los pedidos sociales para la convivencia, no solamente la presencia de niños diversos es la complejidad, nos sentimos retados como adultos a responder con un camino coherente, no sin antes hacer una reflexión de estas dificultades.

El paso de los niños a la dimensión social no siempre es fácil, ni es una facultad que se vaya cumpliendo en todos a cierta edad predecible, cada niño en su particular vida, va forjando su involucramiento en el ámbito social en cuanto ocurre una separación subjetiva de su núcleo vincular, hasta entonces establecido con las personas más cercanas quienes acuden a cubrir sus necesidades cuyos códigos están marcados cotidianamente de afecto y palabras. Esta separación y la manera como se va dando, acaso es 
el forjamiento de la personal manera de desenvolverse en el ámbito social y cuya comprensión nos dan los elementos de estudio de la psicomotricidad.

Es importante hablar también de las necesidades que vemos en los niños afectados con situaciones de cuidado médico, o atravesados por afecciones en su desarrollo como es la parálisis cerebral. De diversas maneras, son niños bastante asistidos, como quienes deben recibir constantemente ayuda sin que se permita que sientan una falta que los motive a buscar por sí mismos el camino a su autonomía, aún en la existencia de una dependencia física, se habla también del forjamiento de una dependencia psíquica.

Debido a las necesidades de intervención terapéutica y médica, son niños tocados constantemente, a veces con intervenciones molestas o dolorosas, acompañados de procesos difíciles exigentes que atañen a su cuerpo y a su movimiento, se ve necesario que puedan construir su imagen corporal, la percepción de sí mismos y de sus límites en la interacción, lo cual es importante acompañar mediante el dispositivo psicomotriz propuesto para que el vínculo con su cuerpo sea también una fuente placentera y no solo de dolor.

La construcción de la imagen corporal toma su importancia tanto para niños con dificultades como sin ella, se diferencia del esquema corporal en que "es el cuerpo vivido, apreciado, aceptado o rechazado". "Es la percepción que tenemos de nuestro propio cuerpo de una manera imaginada, unida a nuestras experiencias libidinales emocionales de nuestros deseos" (Dolto 1984, citado por Rigal 2006).

Por otra parte, la sociedad actual promueve a que los niños se encuentran inmersos dentro de la sociedad de consumo, siendo blanco fácil para influir sobre ellos, es cada vez más accesible para los niños el pedir objetos y que se los otorguen, parece que los niños son ahora objetos de potencial consumo y que sus padres deben cumplir con estas exigencias. Se vende la película con la ropa, con la vajilla, con los cuadernos, con los sellos de cada personaje impreso en todo lo que rodea al niño, los padres también se sienten arrastrados por el sentimiento ilusorio que se desprende de esta concordancia mercantil que se sirve de las emociones, las identificaciones y de las carentes relacionales afectivas.

Este cumplimiento de satisfacciones incide de manera negativa, porque acostumbra a la complacencia fácil de objetos, incluso es más importante el tener que lo que se va a hacer con ello, se compran juguetes antes de que el niño explore las posibilidades con los que ya tiene, y el hambre de tener se abre cada vez más, sobre todo ante las situaciones imposibles de aceptar. La satisfacción con un sucedáneo ocurre en lugar de encontrar formas de sobrepasar los momentos de aburrimiento, de salir airosos del vacío con la creatividad que encierra la respuesta humana acaso con arte, con palabras, con canciones, con baile, con pintura, con representaciones de lo bello, de lo imposible, de lo que molesta y de lo que falta.

Bajo los imperativos de la complacencia de sus propias pulsiones, al centro preescolar vienen cada vez más niños acostumbrados a pedir y menos involucrados en buscar sus propias respuestas, niños que exploran menos y piden más, niños que soportan poco las frustraciones que la vida siempre contrae, niños mas hambrientos de visiones fantásticas que proporcionan los dispositivos tecnológicos, acostumbrados a la velocidad de imágenes, y menos acostumbrados a la paciencia de la observación del mundo real y sus fenómenos.

Entonces el planteo de las sesiones de psicomotricidad fueron encaminadas a coadyuvar a la tarea educativa, formativa, acompañando estos momentos de dificultad por la que atravesamos todos en la primera infancia, en la asimilación de los fenómenos que nos rodean, de las propiedades de los objetos, de las normas que deben ayudarnos a convivir, de los límites propios en el encuentro con los otros, y la forma de involucrarnos lúdicamente con el espacio y con los objetos, sumado a las necesidades de forjar una imagen corporal, fuente de placer y autonomía en los niños afectados por secuelas de lesiones neurológicas y brindar un espacio en donde el niño se encuentre con su potencial capacidad de investigar lo que le rodea y crear. 
El dispositivo psicomotriz nos daría una respuesta precisa a nuestra visión de integralidad sobre el ser humano, integrando aspectos cognitivos, afectivos, perceptivos, motrices y la formación psíquica que habita el cuerpo y el deseo del creciente niño. Como lo resume Bernard Aucouturier "la psicomotricidad se refiere a la construcción somato psíquica del ser humano con relación al mundo que le rodea" (2004). En relación a la terapéutica psicomotriz explica que está encaminada a atender a los niños que tienen una desintegración cuerpo-psique, y que, frente a las angustias, aporta al proceso de aseguramiento, "ancla el registro simbólico en el cuerpo y en los afectos de placer, por medio de una relación interactiva entre niño y terapeuta" (Aucouturier 2004).

En su libro Fantasmas de acción y práctica psicomotriz, Aucouturier se refiere a las angustias vividas en el cuerpo y que tendrían su explicación desde la historia fundante de la persona, desde los orígenes del ser humano, en su vida intrauterina y en las primeras experiencias de vida, y que pueden permanecer a lo largo de la vida del sujeto, presentándose frente a situaciones difíciles. Estas reacciones están muy presentes en la primera infancia y se denominan angustias arcaicas.

En la construcción del ser humano en su inicio de vida, lo psíquico y lo corporal están unidos e indiferenciados, el niño pequeño, dentro del vientre materno percibe la contención de su cuerpo, pero estando fuera, la sensación de unidad se pierde, y cae en momentos en la angustia, ha perdido la sensación de unidad que le da placer, está en un rompimiento somatopsíquico. Al ser contenido retorna el alivio perdido. Es la condición humana de prematuridad que nos acompaña en nuestra etapa infantil que nos hace dependientes de los cuidados externos mientras construimos la autonomía.

Es importante que el niño logre hacer transformaciones, que asimile los cambios de: texturas, movimiento, ambientes, etc., a los cuales va "soportando" gracias a los engranas de acción, que reproducen las sensaciones de alivio provenientes de su madre y en ausencia de ella repite las acciones que le ayudaron a sentir placer, como chuparse los dedos, girar, etc. La palabra cobra un significado que contiene todas estas experiencias aseguradoras. Por lo tanto, en el desarrollo psíquico y psicomotriz estas angustias juegan un papel importante para impulsar al niño a buscar sus propios recursos de alivio.

También es importante señalar que unos niños luchan contra las angustias, pero otro grupo de niños se dejan abandonar por la agonía primitiva, siendo atónicos, silenciosos, inmóviles. La inhibición en estos casos se manifiesta en falta de deseo de acción, deteniendo el interés y búsqueda de objetos y búsqueda de la unidad de sí mismo.

En el ámbito de la psicología es importante saber que estas angustias arcaicas son el germen de las angustias futuras, relacionadas principalmente con el abandono o la separación y con la resolución del problema edípico, tanto en hombres como en mujeres, reviviendo las sensaciones de despedazamiento, caída, dislocación, etc., cuando la castración se hace presente. Lo que se ha visto en niños y en niñas se extiende a otros momentos angustiosos en la vida del individuo que mantendrán latentes, siendo un alimento del sufrimiento y de la depresión.

Es importante en la terapia psicomotriz constatar la presencia de estas angustias vividas en el cuerpo, en el tono y hacer la contención de las mismas, ya que en su momento no existió la forma de hacerlo; la estructuración de la envoltura es débil ya que las transformaciones han sido difíciles, imposibles o dolorosas, sin contención.

\section{Creación del Taller}

Con el apoyo de la psicomotrista Celine Dubreux, quien llegó al Centro San Juan como colaboradora voluntaria, creamos el espacio de Taller, su aporte se reflejó en varios aspectos, uno de ellos, en la creación conjunta del encuadre del taller, el cual tiene la función de brindar un aseguramiento que aporta al desarrollo psíquico del niño.

Este encuadre, diremos que cumple con las funciones de contención que nos habla el psicoanalista y psiquiatra inglés Donald Winnicot acerca de las funciones parentales en la primera infancia, las cuales son la atención a las 
necesidades del bebé, la contención física y emocional como una envoltura de protección que alivie las angustias, y la presentación de los objetos que rodean al niño. El encuadre se refiere a la primera de estas cualidades.

La función del encuadre da al Taller Psicomotriz un efecto contenedor, así como la palabra, los momentos del taller, el accionar del psicólogo hacen parte de este encuadre que en su dinámica va a permitir que los niños resuelvan las dificultades vinculares y sus preguntas.

Al respecto, la terapeuta Claude Sternis nos dice: "Dentro de un grupo terapéutico, ningún mediador, ni el contacto, ni el grupo, ni la palabra, son terapéuticos en sí mismos, solo la instauración del 'encuadré permite a los niños aprovechar las calidades de esta palabra, de este grupo, de este contacto y de este mediador. Estos elementos, permiten crear el vínculo y la distancia entre el niño y él mismo, el niño y los otros niños, y los niños y el animador-terapéutico" (Sternis 1997).

Este encuadre cobra forma con el horario, lugar, reglas de juego, incluso con el material y su forma de utilizarlo. La característica de este encuadre es de ser permanente y sólido, mientras más se quiera evadirlo o sobrepasarlo, más rígido es; sin embargo, permite, pautar los momentos de la experiencia psicomotriz, pautar el dentro del fuera, de lo permitido y de lo no permitido. En la formación del taller, debimos respondernos a las preguntas cruciales para su funcionamiento, como el número de participantes, su ubicación, responder a la demanda de la institución y de los padres de familia, participantes, momentos de enlace con los maestros acerca de los cambios vistos en los niños o la retro alimentación que nos haríamos las facilitadoras acerca del funcionamiento y de la actualización de lo observado en los niños.

Momentos del Taller: referencias de tiempo y espacio

Son referentes que nos acompañan en la vida; sin embargo, nuestra relación con el espacio tiempo, va más allá de los elementos cognitivos, es un aprendizaje relacional que se inicia desde temprana edad cuando salimos de nuestras referencias egocéntricas. Los momentos del Taller, se van repitiendo sesión a sesión marcando a nivel subjetivo la existencia de estos ejes que cruzan nuestra existencia.

\section{El dibujo}

Para el momento de la acogida del taller se presenta un dibujo en donde los niños encuentren un reflejo de las situaciones que comúnmente se vivencian y que pueden no siempre ser de color de rosa; es decir, un dibujo con elementos de la vida real... que represente sentimientos, acaso conflictos y también los valores e ideales... un paisaje con animales, una ciudad con sus atractivos, sus calles oscuras, sus lugares iluminados, etc., colores vivos y colores grises como la gama de sentimientos que existen. El primer día del Taller cada niño podrá elaborar su sello personal y pintarlo o decorarlo, para que sea el símbolo que represente su pertenencia al grupo, siendo el dibujo el espacio que lo contiene y acoge.

\section{El espaciolúdico}

Es un momento marcado por el tiempo, pero dentro del cual los niños tienen la opción de explorar los elementos psicomotrices, luego de un tiempo en que cada uno da paso a su impulsividad, van tomando la necesidad de comunicarse con los otros para construir algo en conjunto, el tiempo juega un papel importante ya que es posible que se agote sin que se llegue a un acuerdo, la presencia del facilitador psicólogo, es para entrar a acompañar esos momentos en donde la pregunta oportuna, o la puesta en palabras del deseo o la desdramatización de los "fantasmas de inhibición" (Aucouturier 2004), aportarían a desbloquear los conflictos y arribar a una construcción social.

El grupo es un momento, un espacio, una verdadera dimensión que se va conformando sesión a sesión, pero que desde un inicio brinda pautas de seguridad, debido al marco de referencia establecido. El lugar preparado con tiempo, las cosas en el lugar preciso, el reloj con el tiempo, el dibujo, la disposición de las sillas, son acciones que ayudan a que los niños tengan el camino marcado por donde transitar y dentro del 
cual pueden establecer los límites a nivel subjetivo.

Es importante resaltar que las psicólogas en el Taller somos las responsables de que el proceso se cumpla dando garantía de que el marco nos contiene, de que las normas que se aplican tienen una utilidad más allá de los ímpetus personales, asimismo su accionar presente y atento a lo individual como a lo grupal.

La dinámica del grupo, las frustraciones vividas, las palabras que acompañan, se van registrando luego de terminar el grupo, añadiendo un tiempo a su finalización para el registro y las reflexiones, que a su vez nos prepararían para la siguiente sesión.

\section{Elmomento de hablar}

Es necesario hacer una distancia entre lo vivido, lo expresado motrizmente, la experiencia lúdica, el encuentro placentero y el conflictivo también con los otros, mediante la palabra. Esta toma de distancia irremediable es la potencialidad humana de apropiarnos de nuestro pensamiento y de nuestros afectos. Los niños van tomando este recurso en la medida de que su palabra es reconocida por los otros, de que su palabra es válida y ocupa el espacio que le corresponde igual que lo ocupan los demás, pero no se obliga ni se impone, es un momento de escucha, de resonancia, de arribar a un puerto seguro que represente a todos y a cada uno.

\section{Cierre}

Para este momento acudimos a un recurso aglutinador como es la canción o el poema, o gestos hablados creados espontáneamente por el grupo, lo cual se vive de manera aglutinadora, con un efecto de placer por lo compartido. De igual manera, cada niño saca su sello del dibujo representando su terminación.

\section{Más allá del juego}

Las exploraciones sensorio motrices con elementos de su interés y de su etapa, permitieron conocer las propiedades de los elementos, y su relación con ellos. No es lo mismo trasvasar agua, que harina, como los granos, los elementos pequeños pueden estar contenidos dentro de un recipiente, a la vez que desarrollaría las habilidades motrices, son la expresión del deseo de explorar y acaso la representación simbólica de sentirse protegidos, contenidos o de salir de un espacio envolvente a explorar otros espacios.

La incursión psicomotriz de movimientos grandes como trepar, reptar, saltar al vacío, subir gradas, va ocurriendo sin la necesidad de una obligatoriedad, los niños se activan dentro de la dinámica lúdica, y al hacerlo van integrando sus angustias corporales, por el acompañamiento tónico y verbal de las psicólogas, incorporando seguridad en las posibilidades de su propio cuerpo.

La función simbólica se pone en marcha con la capacidad de crear juegos y situaciones representativas en donde plasman la comprensión que tienen de su mundo.

A nivel de socialización logran respetar el espacio del otro partiendo de la apropiación de su propio espacio, para llegar a la toma de conciencia del espacio de los otros. El desarrollo afectivo fue importante al comprender las reglas que nos son útiles y al asimilarlas para poder ir a un compartir grupal, por lo tanto, mayor madurez sobrepasando sus estados egocéntricos.

Los niños con dificultades a nivel motor trabajaron la exploración de las posibilidades que su cuerpo les brinda, a nivel sensorial y perceptivo. Muchos de ellos encontraron la relajación y la quietud necesarias para, a pesar de las contracciones de base, que acompaña a su motilidad voluntaria, puedan ejecutar sus deseos y apropiarse de su acción, esto viene debido a que se otorga el tiempo necesario para los niños que se desenvuelven con dificultad, ejecuten a su ritmo las acciones que se proponen.

\section{¿Qué fue lo que hallamos en este camino?}

Mediante el encuadre, sintieron su pertenencia al grupo y se apropiaron de los espacios que se brindan. Cada niño fue cambiando, siendo cada vez más protagonista. Los intercambios entre niños se fueron regulando mediante la asimilación de las reglas, pero también aprendiendo a expresar sus ideas. Detallamos algunos ejemplos a nivel individual: 
Sandra, la niña con parálisis cerebral que tenía tanto miedo de que los niños le toquen, que se acerquen impredeciblemente, la niña que busca siempre dar órdenes para ser sentada en un sofá muy cómodo, es ahora capaz de bajar de su silla, desplazarse hacia la alfombra de juegos, y moverse por entre los módulos disfrutando del movimiento espontáneo, mecerse, resbalar, trepar, son acciones que acompañan a su creación fantástica de mundos e historias que hablan de su vida, y que, llegado el momento, puede abandonar fácilmente para vincularse a la vida y sus exigencias.

Valentina, luego de una experiencia de salto al vacío, venció aquel estado de inhibición que le llevaba a aislarse e involucrarse poco con el movimiento, con la creencia de que la hemiplejía podría afectarle en la exploración de los grandes movimientos, ahora quiere tener mayores retos y habla de ellos.

Naomi, la niña a la que le disgustaba seguir las órdenes del maestro, a quien se le escapaba comúnmente del aula y de las directrices grupales, le costó mucho trabajo y frustración aceptar que las normas nos sirven para la convivencia, lo logró a partir de comprender que los otros ocupan un espacio igual que el espacio que ella puede ocupar y que es igual de divertido quedarse a construir con sus amigos que salir y aislarse. Fue haciendo una elección personal, abandonando el egocentrismo con la confianza en el grupo.

A nivel del equipo de profesionales, gracias a los efectos positivos de los talleres, se ha podido hablar del proceso de cada niño con el resto de compañeros del servicio terapéutico y educativo, aportando a la comprensión global de las necesidades y perspectivas futuras de cada niño.
Estos talleres fueron sostenidos, a su vez, por nuestros interlocutores, los maestros de aula, quienes tienen la apertura para escuchar las sugerencias y observar los cambios de los niños.

Sabemos que, por el impacto positivo, se puede extender el servicio de estos talleres a otras poblaciones, acaso grupos de aula de escuelas afectadas por distintos problemas sociales y relacionales y aplicarlos con las debidas variaciones a otros grupos de edad.

Es importante contar con el vínculo constante con los padres de familia de los niños, estableciendo entrevistas individuales al iniciar, en el camino y al finalizar el ciclo.

La terapia psicomotriz ha sido efectiva para todos los niños en cuanto al desarrollo de mayor autonomía y el desarrollo de su personalidad, al saberse dentro del grupo, al sentir que su palabra tiene una resonancia en los demás que es válida, aprenden a abandonar los temores a relacionarse y la respuesta de aislamiento es desactivada.

También nos anima a seguir profundizando en el conocimiento teórico práctico de la psicomotricidad con su visión desde el aspecto relacional y a seguir proponiendo estos espacios tan necesarios en estas épocas de tendencia al aislamiento y a la pobreza relacional.

Al transcurrir el año lectivo, por el accionar de todos, tanto educadores como padres de familia, psicólogos y terapeutas, el pequeño caos del patio de juegos es cada vez más un lugar de creación placentera y de compartir.

\section{REFERENCIAS}

Aucouturier, B. (2004). Los fantasmas de acción y la prácticapsicomotriz. Barcelona: Graó.

Dolto, F.(1984). La dificultad devivir.

Rigal, R. (2006). Educación motriz y educación psicomotriz en Preescolar y Primaria. Barcelona: INDE publicaciones.
Sternis, C. (15 de 04 de 2012). Le Journal des psychologues. Revisado el 26 de marzo de 2014 de Le Journal des psychologues: asphodele-ateliersdupre.perso.sfr.fr

Winicott, D. (1980). La familia y el desarrollo del individuo. Barcelona: Paidós. 